\title{
Transitioning from Conventional to Organic Farming Using Conservation Tillage ${ }^{1}$
}

\author{
D. L. Wright, J. Moyer, D. Treadwell, I. M. Small, and S. George ${ }^{2}$
}

Organic farming is one of the fastest-growing segments of the agricultural industry in the United States and in Florida. Conservation tillage (CT) is often employed to reduce soil erosion, improve physical and biological properties of soil, and increase water use efficiency. Although the practice of CT is used widely in conventional agronomic cropping systems, CT is also a feasible strategy to assist with the transition from conventional farming to organic farming. This article aims to provide recommendations to row crop farmers who wish to implement CT practices during their transition to a certified organic system.

Farmers who choose to implement organic systems strive to achieve balance between economic and ecological sustainability. The cost of producing organic crops is often greater than conventional production due to the additional labor associated with implementing enhanced ecological management strategies and the relatively higher costs of fertility and pest management inputs that are approved for use in organic systems. The use of non-synthetic fertilizers and crop protection products to ensure environmental stewardship is allowed, but only as a last resort; the organic program emphasizes proactive cultural strategies to optimize crop quality and yield. These additional costs are often offset by a price premium that organic farmers receive for their products. The transition process from conventional to organic farming needs to include practices that are compatible with environmental stewardship and social responsibility. This is where CT can help. With proper planning and attention, it is possible to transition while maintaining CT practices.

\section{Weed Management}

For many Florida row-crop farmers who have been growing crops using conservation tillage or no-tillage with cover crops, transitioning to organic crop production may seem like a step backwards in soil and water conservation and environmental stewardship. For instance, a major challenge in Florida during the transition stage is weed control, especially for perennial grasses such as bermudagrass (Cynodon dactylon), and annuals that produce seed readily such as palmer amaranth (Amaranthus palmeri) and teaweed (Sida rhombifolia). Weeds that employ both seed and vegetative strategies for reproduction such as nutsedge (Cyperus rotundus; Cyperus esculentus) and tropical spiderwort (Commelina benghalensis) may increase in density during repeated mechanical cultivation events. The weeds commonly found on farms, especially perennial weeds, are species that have developed resistance to

1. This document is SS-AGR-11, one of a series of the Agronomy Department, UF/IFAS Extension. Original publication date March 2006. Revised September 2012, March 2013, December 2016, and November 2020. Visit the EDIS website at https://edis.ifas.ufl.edu for the currently supported version of this publication.

2. D. L. Wright, professor, Agronomy Department; J. Moyer, CEO, Rodale Institute; D. Treadwell, associate professor, Horticultural Sciences Department; I. M. Small, assistant professor, Plant Pathology Department; and S. George, biological scientist, Agronomy Department, UF/IFAS North Florida Research and Education Center; UF/IFAS Extension, Gainesville, FL 32611.

The use of trade names in this publication is solely for the purpose of providing specific information. UF/IFAS does not guarantee or warranty the products named, and references to them in this publication do not signify our approval to the exclusion of other products of suitable composition.

The Institute of Food and Agricultural Sciences (IFAS) is an Equal Opportunity Institution authorized to provide research, educational information and other services

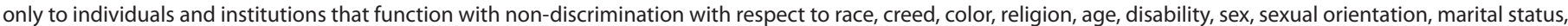

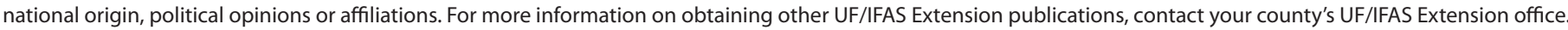
U.S. Department of Agriculture, UF/IFAS Extension Service, University of Florida, IFAS, Florida A \& M University Cooperative Extension Program, and Boards of County Commissioners Cooperating. Nick T. Place, dean for UF/IFAS Extension. 
conventional farming and historical production practices. A common organic farming practice to reduce the weed seed bank is the stale seed bed method, which uses repeated shallow cultivations at the white hair root stage until the rate of weed seed emergence in the top few inches of soil decreases. This method is most productive after a rain event because the rain stimulates weed emergence, after which cultivation events will be more productive. Farmers may till the land as many as 3-6 times during a single growing season, depending on the crop, to "eradicate" weeds and prevent reseeding before they start organic farming. This is a "deal with it now and not worry about it in the future" approach. However, this practice often fails to yield desired results. Repeated cultivation leads to soil erosion and subsequent loss of organic matter from Florida soils. Farmers acknowledge soil erosion in organic farming operations, but often prioritize weed management over soil conservation. Developing an organic CT system that also manages weeds effectively is critical to the system's profitability and success.

\section{Insect and Disease Management}

Pesticides approved for use in organic systems can be less effective than their conventional counterparts. It may require additional applications of compliant pesticides and more hand labor to obtain results similar to conventional pest management programs. Many farmers report a reduction in insect and disease occurrence and severity as they adopt more ecologically based management practices. Cultural strategies such as timing of plant, cultivar selection, and scouting are critically important. Once the crop is established, management options for supplemental pesticides are limited.

\section{Maintaining Soil Organic Matter}

The importance of balancing healthy soil and effective weed management in organic farming cannot be overemphasized. The most important underlying principle of organic farming is the building of healthy soils with good structure, high organic matter, diverse soil micro- and macrofauna, and high water-holding capacity. Such soils can support plant health and better resist pests (Organic Farming Research Foundation 2003). Loss of nutrients and organic matter through mismanagement depletes soil fertility. Furthermore, sediment runoff water contaminates water bodies, causing environmental degradation. Fertilizers in organic systems are primarily derived from plant and animal by-products or mined minerals. They do not provide the same readily available nutrients as conventional, salt-based fertilizers such as ammonium nitrate. Thus, conserving soil fertility and improving the soil's capacity to retain those nutrients are very important. The building of soil organic matter is a gradual, long-term process, and even with the best conservation measures, soil organic matter only increases at a rate of $0.1 \%-0.2 \%$ per year (Martin 2003). Reducing tillage is a key strategy to protect and build soil organic matter.

\section{Crop Rotation and Cover Crops}

The apparent conflict between use of sustainable crop management products (organic-approved pesticides) and non-sustainable farming operations (increased tillage) can be mitigated by considering crop rotations to diversify the timing of tillage and planting, as well as cover crops to reduce the negative impacts of tillage operations. Conservation tillage along with use of cover crops is an efficient way to manage weed growth and protect soil health while transitioning from conventional to organic farming (Figure 1). Subsoiling may be essential, as is normal practice with strip tillage, if the compaction layer has not been penetrated by roots of perennial grasses. This practice may also be necessary if perennial grasses are not completely decomposed, or if perennial grasses are not being used in the rotation at all. Subsoiling improves water infiltration, porosity, bulk density, and soil crumb structure. It also results in better root growth in the area of the subsoil pass.

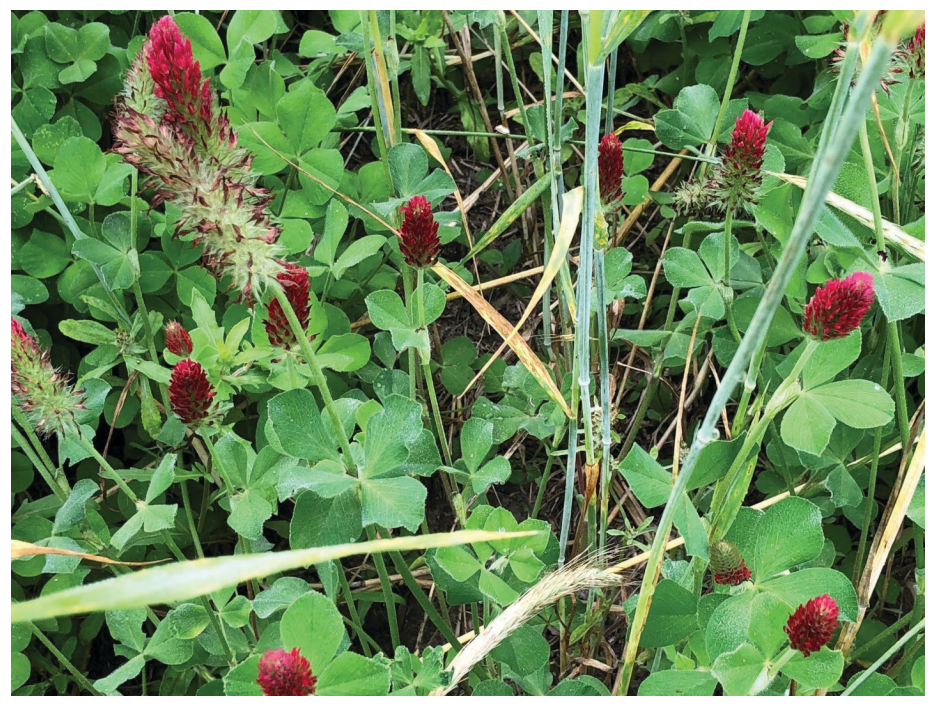

Figure 1. A cover crop blend of crimson clover 'Dixie' and 'FL 401 cereal rye' prior to termination.

Credits: Danielle Treadwell, UF/IFAS

With careful selection of cover crops and techniques to prevent their competition with the primary crop, conservation tillage can be successfully used for organic farming. Physical means such as rollers can terminate cover crops (Figure 2). Rollers or roller crimpers roll down high-residue cover crops such as rye and oats when the stems have elongated to produce the seed head. The crop is killed by 
breaking the stem near the ground (Figure 3). Cover crops can also be terminated naturally via frost or heat, or by scheduling a rotation that allows the cover crop to mature prior to planting the cash crop.

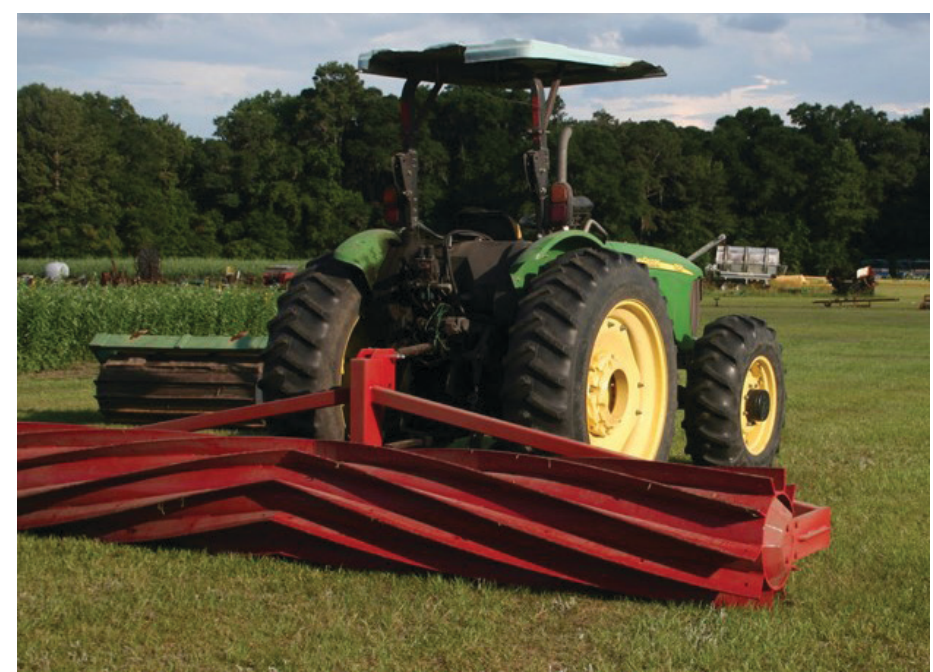

Figure 2. A ten-foot commercially available roller crimper for row crop production.

Credits: Danielle Treadwell, UF/IFAS

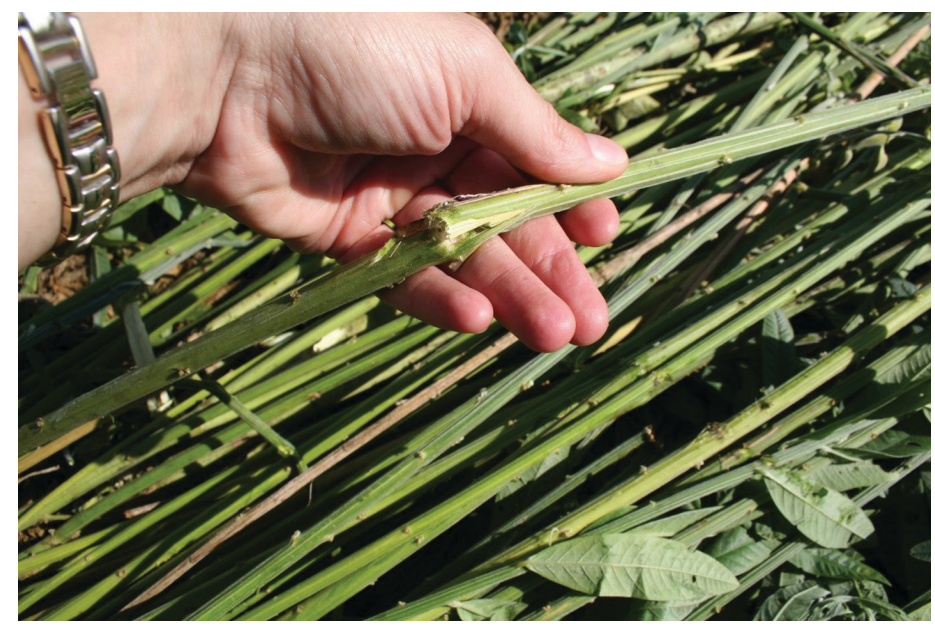

Figure 3. The effect of roller crimping on stems of the tropical legume sunn hemp. Note the bending in the stems.

Credits: Danielle Treadwell, UF/IFAS

A high-residue cover crop can smother out many weeds and help to build soil organic matter (Figure 4). Planting a mixture of grasses or a mixture of grasses and legumes immediately after tillage is suggested to reduce losses due to erosion.

One good combination of grasses includes a mixture of millet and bahiagrass. Millet establishes quickly and can prevent erosion during the early stages of succession. Bahiagrass is among the best-adapted grasses for Florida. It is deep-rooted and can take up nutrients and recycle them from greater depths in the soil horizons, especially if cattle are grazed on it. These nutrients would otherwise be unavailable to the system. Bahiagrass must be terminated by tillage or smother crops. When bahiagrass dies, the roots decay and create channels in the soil profile, which increase aeration and water infiltration. Bahiagrass grows well on less fertile soils and can outcompete encroaching weeds (Kalmbacher 2003). Bahiagrass, however, takes longer to establish; therefore, planting it with millet or other faster-growing annuals is recommended. Once established, the millet can be mowed or grazed, allowing bahiagrass to dominate the mixture. Bahiagrass may have to be chisel-plowed prior to planting a cash crop to reduce competition. The strip-till rig may need to be run twice before planting in the same row. Tillage on bahiagrass could be done in the fall and overseeded with rye, with the rye rolled down in late March prior to planting vegetable crops. Other examples of cover crops include soybean, annual ryegrass, and small grains, all of which have aggressiveto-intermediate rates of establishment. Alfalfa can also be used, but like bahiagrass, it has a slow rate of establishment (Wright et al. 1978) and must be grown in conjunction with more aggressive species to prevent erosion.

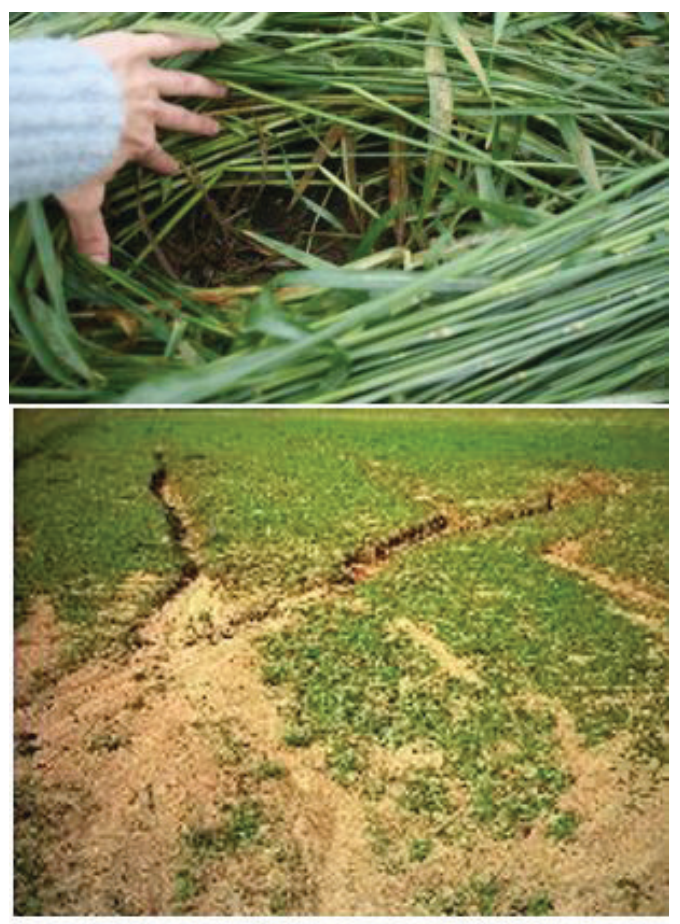

Figure 4. (A) A cover crop of 'FL 401' cereal rye (Secale cereal) immediately after roller-crimping. (B) Consequences of tilling and leaving the land barren during periods of high rainfall.

Credits: (A) Danielle Treadwell, UF/IFAS. (B) UF/IFAS

Small-grain cover crops can be planted into bahiagrass late in the fall with strip tillage or no-till drills. Small-grain crops need nitrogen in the winter to generate adequate residue, which can be rolled in the spring to smother the bahiagrass. Legumes (peas, sunn hemp, or beans) may 
be planted to recharge the soil nitrogen before another nitrogen-requiring cash crop is planted.

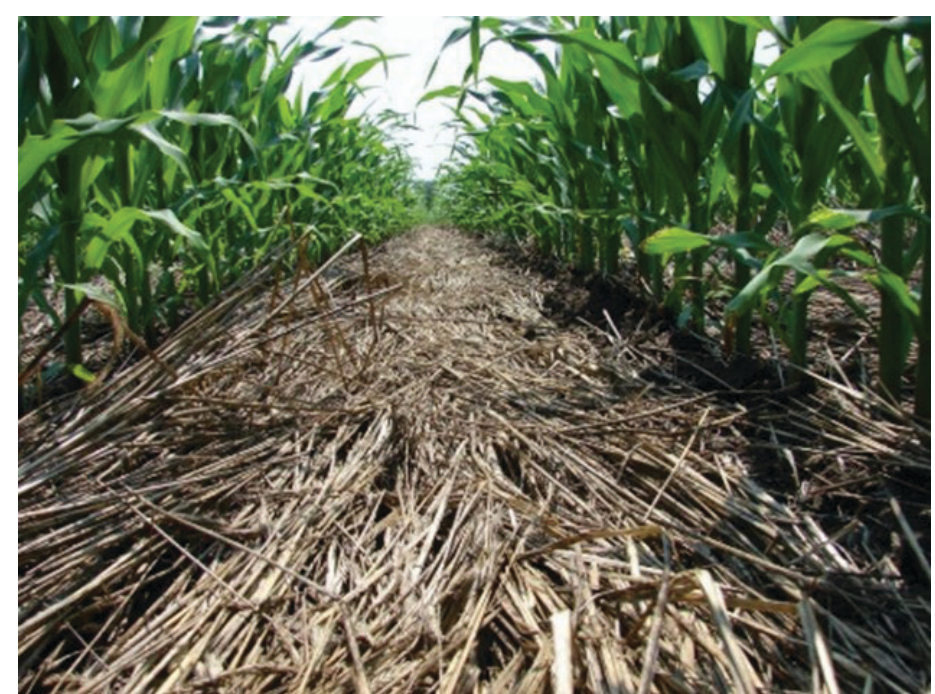

Figure 5. Organic corn planted in a cover crop of roller-crimped rye and hairy vetch.

Credits: Danielle Treadwell, UF/IFAS

Forage legumes can also be seeded with bahiagrass. This practice will add nitrogen to the soil. Both summer and winter legumes can be used. The legumes can be drilled into bahiagrass with a no-till drill or overseeded into bahiagrass after it has been chopped. Burning bahiagrass to establish a good legume crop is not generally recommended because it results in loss of organic matter. Grazing to reduce the biomass of bahiagrass would be ideal if it met requirements for food safety (http://sustainableagriculture. net/wp-content/uploads/2008/08/NSAC-Food-SafetyPolicy-Brief-October-20091.pdf). The seed mixtures should be chosen carefully depending on the time of year and plans for the next crop. Inoculant is an inexpensive addition to legumes to improve stand, particularly if the field has not been in legumes for three or more years. Farmers can consult their local UF/IFAS Extension agents or Extension forage specialist to select appropriate legumes, seeding rates, and planting method.

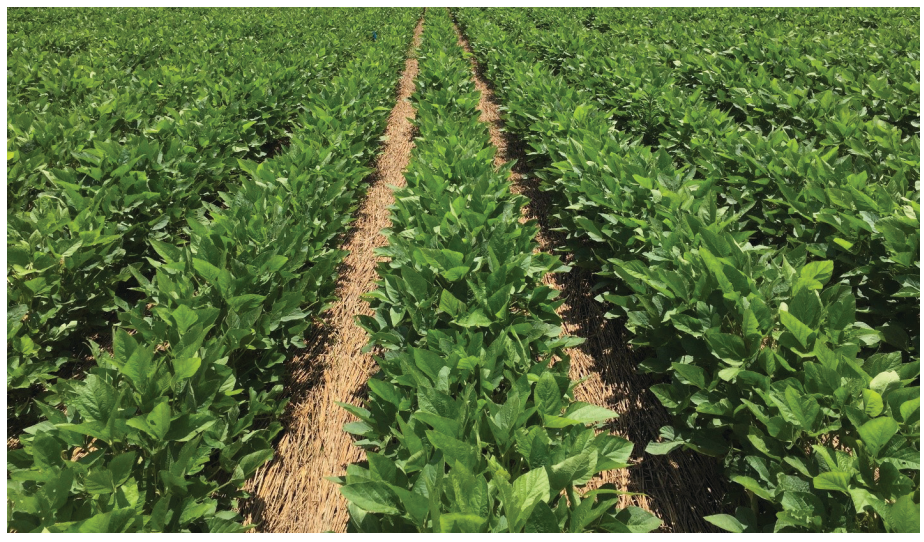

Figure 6. Soybean in a no-till field.

Credits: Danielle Treadwell, UF/IFAS
While it is more costly in the short term to till the land or use a no-till drill and plant cover crops compared to tilling the land and leaving it barren, a well-managed soil is a worthwhile investment with long-term returns. A healthy soil with high organic matter and good structure is indispensable for high productivity. Organic matter should be viewed as a "revolving nutrient bank account" because it is a storehouse of plant nutrients, which are released to plants upon decomposing. Hence, loss of this "bank account" should be prevented (Agriculture, Food, and Rural Development 2003).

Talking with organic growers about the challenges they have faced and the ways they addressed those challenges is beneficial to any new producer. Farmers who are already certified organic are required to get approval from their certification agency before implementing any new practice. If you are new to organic systems, consult EDIS document HS720, Introduction to Organic Crop Production (https:// edis.ifas.ufl.edu/cv118). The National Organic Standards are available on the National Organic Program website at http://www.ams.usda.gov/AMSv1.0/nop. Cropland can be certified as organic only after the land has been free of prohibited inputs or practices (e.g., most synthetic fertilizers and pesticides) for 36 months. This usually requires planning so that the soil is adequately fertile and as free of weeds and other pests as possible before organic production can begin. Growers should identify crops that can most easily be grown and marketed at a time of the year when pests are at low levels. Many growers start with small acreage while still growing other crops using conservation tillage/conventional practices. This allows growers to "test the waters" and gradually transition into organic farming while gaining valuable experience with the usual challenges, opportunities, and available markets. In addition to the standards stated in the website above, UF/IFAS Extension county faculty and the Florida Organic Growers and Consumers Association (http://www.foginfo.org/) can provide information and advice to new growers on certification, fees, applications, inspection, and reporting. Access to appropriate equipment can be a limiting factor because there is a greater emphasis on cover crop management in organic systems. Regional Water Management District offices and Natural Resources Conservation Service (NRCS) offices can provide information about cost share programs on equipment that will conserve soil and protect water (https://www.sjrwmd.com/localgovernments/funding/agricultural-cost-share/; http://www.srwmd.org/366/ Agricultural-Cost-Share-Program; https://www.nrcs.usda. gov/wps/portal/nrcs/main/national/programs/financial/ eqip/). 


\section{Tips for Transitioning from Conventional to Organic Farming Practices}

- Select fields with well-drained soils, adequate waterholding capacity, adequate fertility, ideal $\mathrm{pH}$ levels, and history of no to light weed pressure, that are well rotated so that disease and nematode pressure is not a concern.

- Plant cover crops that will grow vigorously prior to the cash crop that can be killed by rolling or frost, or will mature prior to planting the cash crop.

- Soybeans, sunn hemp, or millet can be drilled late in the season and killed by frost, rolled, or killed with organic materials. This will result in a thick ground cover that can be planted into for fall crops (cole crops).

- Rye or oats can be planted early in the fall and killed by rolling with a roller after they head in the spring (late March) for a thick ground cover, which will help control weeds and hold moisture for a spring crop (cole crops or other summer crops).

- Plant crops during a season that is relatively free of pests. Cole crops may work well for a first crop planted in late August or early March.

- Monitor environment and weeds to perform all operations in a timely manner.

- Select varieties known to express good seedling vigor to better compete with weeds.

- If irrigation is not available, choose crops that grow in a seasonal period when rainfall is adequate. The most consistent period for rainfall and moderate climate with few pests usually occurs from January through April.

- Apply composted chicken manure, mushroom compost, or other types of weed-free organic matter when available, to keep soil fertile and increase organic matter. Monitor soil zinc, copper, and phosphorus accumulation over time to prevent toxicity.

- Use as little tillage as possible because tillage degrades soil structure, causes erosion, reduces soil organic matter, and may result in lower yields. Strip-till rigs that only open a slit for row crops may be used for vegetables as well as other crops while suppressing weeds and conserving moisture. Tillage may be necessary on some perennial grasses but may still have adequate soil cover to slow erosion and maintain $30 \%$ or more ground cover while the crop is growing.

- Use perennial grasses (e.g., bahiagrass) in the rotation if possible, because weeds, disease, and nematodes are reduced. Grasses facilitate greater accumulation of soil organic matter than legumes. Yields of many crops have been shown to be higher after perennial grasses, which are preferred in peanut, watermelon, and other highvalue cash crop rotations.

- If possible, incorporate livestock grazing as part of a soil improvement and weed management strategy.

- If grazing is done on a winter cover crop, a row crop will have to be planted prior to planting a vegetable crop to meet food safety requirements.

- Leguminous cover crops decompose quickly and may not protect the soil from erosion or provide all-season weed management.

- Before planting a cash crop, learn about organic farming practices suited to the crop and explore the markets for your products. Learn from those who have done it successfully.

\section{References}

Agriculture, Food, and Rural Development. 2003. "Soil Organic Matter." Alberta Government. http://www1.agric. gov.ab.ca/\$department/deptdocs.nsf/all/agdex890

Kalmbacher, R. S. 2003. "Establishment of Legumes in Bahiagrass Sod." http://www.ag.auburn.edu/auxiliary/nsdl/ scasc/Proceedings/1980/Kalmbacher.pdf

Martin, H. 2003. “Transition to Organic Farming." Ministry of Agriculture and Food. Ontario. http://www.omafra.gov. on.ca/english/crops/facts/10-001.htm

Organic Farming Research Foundation. 2003. "How do organic farmers fertilize and control pests, diseases, and weeds?" http://ofrf.org/organic-faqs

Wright, D. L, R. E. Blaser, and J. M. Woodruff. 1978. "Seedling Emergence as Related to Temperature and Moisture Tension." Agronomy Journal 70: 709-712. 